\title{
MAPEAMENTO DOS CLUBES DE CIÊNCIAS DA AMÉRICA LATINA E CONSTRUC̣ÃO DO SITE DA REDE INTERNACIONAL DE CLUBES DE CIÊNCIAS
}

\author{
DANIELA TOMIO ${ }^{*}$ \\ https://orcid.org/0000-0001-5578-7822 \\ ANDIARA PAULA HERMANN" $1 *$ \\ https://orcid.org/0000-0002-3556-8603
}

RESUMO: No Brasil e em outros países da América Latina

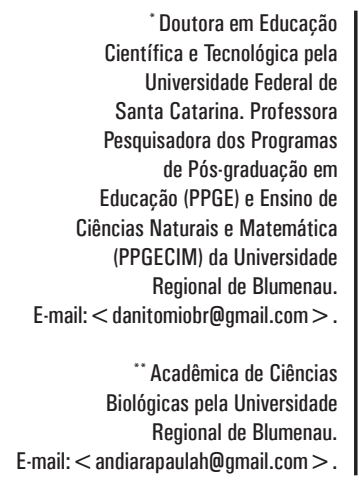

Foi possível mapear Clubes de Ciências distribuídos em doze países e com as informações sistematizadas podemse produzir conhecimentos que permitem aprender sobre estes contextos em sua diversidade de experiências.

Palavras-chave: Ensino de Ciências; Clubes de Ciências; América Latina; Práticas Educativas.

\section{MAPEO DE LOS CLUBES DE CIENCIAS DE LATINOAMÉRICA Y CONSTRUCCIÓN DEL SITIO WEB DE LA RED INTERNACIONAL DE CLUBES DE CIENCIAS}

RESUMEN: En Brasil y en otros países de Latinoamérica, existen colectivos que buscan, por medio de los Clubes de Ciencias, romper la forma tradicional de organización de los tiempos y los espacios destinados convencionalmente por las escuelas a la enseñanza de Ciencias. De ese modo, se pretendió investigar modos de organización de Clubes de Ciencias con objeto de mapear y compartir experiencias de esos contextos escolares. Para ello, se realizó una investigación en internet de Clubes de Ciencias de escuelas

\footnotetext{
I Universidade Regional de Blumenau, Programas de Pós-graduação Ensino de Ciências Naturais e Matemática, Blumenau, SC - Brasil.

" Universidade Regional de Blumenau, Acadêmica de Ciências Biológicas, Blumenau, SC - Brasil.
} 
de países latinoamericanos. Con el levantamiento, se elaboró un sitio web, que se constituyó en la Red Internacional de Clubes de Ciencias. Fue posible mapear Clubes de Ciencias distribuidos en doce países, y con las informaciones sistematizadas, se pueden producir conocimientos que posibiliten aprender estos contextos en su diversidad de experiencias.

Palabras clave: Enseñanza de Ciencias; Clubes de Ciencias; Latinoamérica; Pratiques Éducatives.

\section{MAPPING SCIENCE CLUBS IN LATIN AMERICA AND BUILDING THE WEBSITE OF THE INTERNATIONAL SCIENCE CLUBS NETWORK}

ABSTRACT: In Brazil and especially in other Latin American countries, there are collective that have sought, with the Science Clubs, to break the traditional way of organizing time and space conventionally destined by schools to the Science teaching. With this objective in mind,the organization and functioning of Science Clubs were investigate in order to map and share innovative experiences in school contexts. For that, a research was conducted on the Internet of Science Clubs of schools in Latin American countries. With the survey, a website was created, constituting the International Network of Science Clubs. It was possible to map Clubs of Sciences distributed in twelve countries that have channels of diffusion and communication by the Internet. With systematized information, knowledge can be produced that allows learning about these contexts in their diversity of experiences.

Keywords: Science teaching; Science Clubs; Latin America; Educational Practices. 


\title{
INTRODUCุÃO
}

\begin{abstract}
O que não é chamado não existe. Para algo ter um lugar no discurso e para que possa ser reconhecido, na realidade, essa coisa deve ser chamada. Na pedagogia faltam nomes, conceitos e slogans que poderiam ser responsáveis, assinar e divulgar as áreas de ensino para o qual estamos falando. (BERNET, 2013, p. 33, tradução nossa)
\end{abstract}

É na intenção de fazer existir, dar visibilidade e "para que possa ser reconhecido" no ensino de Ciências que desenvolvemos e socializamos essa pesquisa que tem como contexto os Clubes de Ciências. No Brasil e, principalmente, em outros países da América Latina, desde a década de 1950, existem coletivos que têm buscado com os Clubes de Ciências, romper com a forma tradicional de organização dos tempos e espaços destinados convencionalmente pelas escolas para o ensino e a aprendizagem das Ciências da Natureza.

O Clube de Ciências se configura como espaço de educação constituído por estudantes, livremente associados e que se organizam como grupo que compartilha o interesse pela ciência e o desejo de estarem juntos. Nestes contextos, os clubistas, acompanhados por um professor de Ciências, desenvolvem atividades investigativas, culturais, de expressão e cooperação, a partir de temas de seus interesses. (ROCHA; KERN; MELO; TOMIO, 2015). Assim, o Clube passa a ser um lugar onde o estudante tem a possibilidade de apropriar-se de conhecimentos científicos bem como dos seus processos de produção, além de cultivar o gosto pela atividade científica e a reflexão de suas implicações sociais. (PRÁ; TOMIO, 2014). Em outras palavras, o Clube de Ciências “[...] conduz os estudantes a níveis mais sofisticados de conhecimentos, o que caracterizaria uma cultura científica, frente às complexidades determinadas pela evolução científica e tecnológica do mundo moderno, suas aplicações, consequências e limitações" (MENEZES; SCHROEDER; SILVA, 2012, p. 815).

Podemos ressaltar, também, que os Clubes de Ciências possibilitam o desenvolvimento da imaginação e da criatividade, além de viabilizar a interação com o meio físico e social, estimulando nos estudantes a curiosidade, a problematização e a busca por soluções para questões dos seus contextos, representando num significativo impulso para a aprendizagem científica, o desenvolvimento da autonomia e das relações sociais. (MENEZES; SCHROEDER, 2014). Nesses processos, os clubistas aprimoram linguagens, que se materializam na forma oral e escrita, ou seja, no processo de constituição de sujeitos-autores, na medida em que aprendem e se desenvolvem.

Um diferencial do Clube de Ciências como contexto para educação científica é que o desenvolvimento de suas atividades é sempre em uma dimensão que privilegia o trabalho cooperativo de um coletivo na escola. Nele, um estudante é o "clubista", ou seja, ocupa um lugar que se caracteriza pelas relações com outros clubistas, mediadas por saberes da ciência, constituindo o "clube". Nesta perspectiva, defendemos que o Clube de Ciências pode se constituir num contexto privilegiado para inclusão dos participantes em torno de um objetivo comum aprender ciência na escola, convivendo com as diversidades na forma de se relacionar com o mundo, no mundo. (ROCHA; KERN; MELO; TOMIO, 2015). 
Em pesquisas de estado da arte Prá e Tomio (2014); Santos (2017) e Schmitz (2017) identificaram no Brasil uma expressiva produção acadêmica sobre Clubes de Ciências com contribuições para o ensino de Ciências no país, cuja disseminação em eventos e periódicos tem permitido o intercâmbio de saberes e práticas com professores e pesquisadores. Tal evidência, também, nos permitiu interpretar uma lacuna em estudos sobre Clubes de Ciências que sistematizem conhecimentos que possibilitem ao coletivo de educação científica organizarse, compartilhar e produzir experiências compartilhadas sobre estes espaços de aprender Ciências na escola.

Além do Brasil, em um levantamento panorâmico, pela internet, de experiências de escolas com Clubes de Ciências em países como Argentina, Uruguai, Chile, Equador, Peru, entre outros latino-americanos, observou-se que existem iniciativas consolidadas nas escolas, já há muito tempo, com disseminação de práticas até entre os Clubes, formação de professores, atividades amparadas na legislação, com intersetorialidade entre políticas públicas de Ministério da Ciência e Tecnologia com o Ministério da Educação. Na América Latina há referências aos Clubes de Ciências em funcionamento em vários dos seus países já na década de 1950 (MANCUSO; LIMA; BANDEIRA, 1996). No ano de 1984, em Santiago do Chile, um coletivo de especialistas organizou o "Manual para el fomento de las atividades cientificas y tecnologicas juveniles", com um capítulo específico sobre os Clubs de Ciencias, produto da Oficina Regional de Educación da UNESCO para América Latina y Caribe" a fim de incentivar a criação destes espaços para o desenvolvimento da educação científica. (SECAB UNESCO, 1984).

Diante desse cenário, objetivamos investigar modos de organização e funcionamento de Clubes de Ciências da América Latina a fim de mapear e compartilhar experiências inovadoras em contextos escolares de ensino de Ciências.

Atualmente, em tempos que a educação tem as suas possibilidades ampliadas pelas tecnologias digitais, compreendemos que o mapeamento e a constituição de um banco de informações sobre a organização dos Clubes de Ciências no Brasil e expandindo para países da América Latina pode contribuir para produção, difusão e intercâmbio de saberes entre "clubistas", "professores de Ciências", "pesquisadores" dentre outros, na motivação de uma identidade latino-americana para os Clubes de Ciências, bem como inspirando políticas e programas públicos de Educação.

Justificamos um universo da pesquisa latino-americano, pois, defendemos que é preciso sistematizar e construir constructos teóricos das pesquisas de países da América Latina, oriundas dos movimentos sociais, conectadas às tradições populares e aos problemas emergentes da nossa realidade histórico-social-cultural. Isso tem relação com o desafio e internacionalização da pesquisa em educação, no diálogo com pesquisadores de outros países e na ampliação da autoria brasileira a partir da divulgação de nossos estudos em outros cenários.

Nesta direção, compreendemos que produzir conhecimentos sobre Clubes de Ciências, que permitam aprender sobre estes contextos de educação, tem relevância para comunidade científica de Ensino de Ciências, com a possibilidade de compartilhar coletivamente experiências sobre os Clubes de Ciências, que contribuam para a interinstitucionalidade e internacionalização em ações cooperativas de produção e socialização do conhecimento sobre e na escola. 
A partir disso, foram nossos objetivos específicos de pesquisa: a) mapear Clubes de Ciências distribuídos em escolas de diferentes países da América Latina, que possuem canais de difusão e comunicação pela internet e b) elaborar um inventário das práticas que têm sido mediadoras do funcionamento de Clubes de Ciências em escolas latino-americanas.

Além da investigação desses objetivos, como produto dessa pesquisa, construímos o site da "Rede Internacional de Clubes de Ciências" (RICC), que congrega Clubes de Ciências em funcionamento em escolas latino-americanas e uma biblioteca com documentos (pesquisas, manuais, mídias) sobre esses contextos de educação científica. Esse mapeamento e caracterização dos Clubes de Ciências, bem como a construção da RICC serão abordados nas próximas seções.

\section{PERCURSO INVESTIGATIVO}

Para atingir os objetivos da pesquisa foram desenvolvidos os seguintes procedimentos metodológicos:

a) inventário de Clubes de Ciências em funcionamento em escolas de países latino-americanos e que possuem suas atividades divulgadas na internet. Para isso, a técnica utilizada na coleta de dados foi a observação em pesquisas exploratórias na internet em sites de busca, como 'Google'; em redes sociais como Facebook e Pinterest e em canais de vídeos no Youtube. Empregamos para busca as palavras-chave: "clube/s de ciência/s" e "club de ciencia". Além disso, configurou-se a ferramenta de busca Google para o levantamento dos Clubes de Ciências em sites próprios dos países, como, por exemplo, www.google.ar (Argentina); www.google.co (Colômbia), dentre outros. Foram adotados esses procedimentos para os vinte países que compõem a América Latina (Argentina, Bolívia, Brasil, Chile, Colômbia, Costa Rica, Cuba, Equador, El Salvador, Guatemala, Haiti, Honduras, México, Nicarágua, Panamá, Paraguai, Peru, República Dominicana, Uruguai e Venezuela);

b) elaboração de um instrumento de coleta de dados para identificar as informações sobre Clubes de Ciências em funcionamento nas escolas de países da América Latina que foram identificados. Elaboramos um formulário, com auxílio da ferramenta Google, que foi respondido online pelos professores responsáveis pelos Clubes de Ciências. O instrumento foi organizado em dois idiomas: Português e Espanhol, com perguntas de respostas discursivas e outras de respostas objetivas. Esse formulário foi alocado em um site intitulado Rede Internacional de Clubes de Ciências (RICC), construído também com a pesquisa. Assim, a resposta ao formulário, já inscrevia o Clube de Ciências nesse espaço virtual.

c) correspondência, via e-mail, com os responsáveis pelos Clubes de Ciências identificados, para responderem o formulário da pesquisa/inscrição do Clube de Ciências na RICC. Importante destacar, que o instrumento 
de coleta de dados previa ao respondente, responsável pelo Clube de Ciências, identificar-se e autorizar (ou não) a divulgação das informações respondidas. Todos os respondentes consentiram o uso dos dados na pesquisa e sua publicação no site da RICC;

d) com os dados coletados no ato da inscrição na RICC foi possível organizar um inventário inicial de informações dos Clubes a partir de categorias de análise elaboradas a priori, considerando informações solicitadas no formulário: nome do Clube de Ciências, endereço/país, ano de início do funcionamento, local de funcionamento: escola - pública, privada ou outro; nível educativo dos participantes, número de participantes, requisitos formais (leis, políticas públicas...) para funcionamento do clube no país, iniciativa para implantação do Clube de Ciências, apoio financeiro, parcerias com outras instituições, atividades/projetos desenvolvidos, formas de planejamento das atividades, temas investigados, canais de mídia para divulgação dos clubes.

Esses dados, gerados com as respostas dos responsáveis de cada Clube de Ciências em particular, foram compilados, considerando cada país de origem. Além disso, com os países identificados, buscamos outras informações, explorando sites oficiais de Ministérios da Educação ou de Ciência e Tecnologia a fim de complementar nossas análises.

\section{OS CLUBES DE CIÊNCIAS NA AMÉRICA LATINA: MAPEAMENTO E CARACTERIZAC̣ÃO}

Destacamos os resultados na pesquisa, considerando os seus objetivos específicos. Inicialmente buscamos mapear os Clubes de Ciências distribuídos em escolas de diferentes países da América Latina, que possuem canais de difusão e comunicação pela internet.

Foi possível identificar, no período de setembro/2015 a 30/09/2017, o total de 278 Clubes de Ciências em funcionamento, com sites e/ou redes sociais, distribuídos em doze países da América Latina.

Foram considerados apenas os Clubes de Ciências em atividade, desconsiderando aqueles com sites/redes sociais não atualizados nos últimos 12 meses. De cada país foi elaborado um quadro com o nome dos Clubes de Ciências e respectivo endereço online. ${ }^{1}$

Importante destacar que nos sites oficiais dos governos de países que possuem políticas públicas e/ou atividades relacionadas aos Clubes de Ciências há referências sempre para uma quantidade maior do que foi possível identificar na busca online. Assim, infere-se que muitos Clubes não possuem canais de comunicação e difusão na internet (blogs ou redes sociais). Exemplo disso, no Peru identificamos 5 Clubes de Ciências que possuíam redes sociais, no entanto um por eles, do Consejo Nacional de Ciencia, Tecnologia e Innovación Tecnológica, nos informou via uma carta, por e-mail, que o país contava com 143 Clubes de Ciências, mas que não possuíam mídias sociais.

Com nosso método de busca não foi possível identificar nenhum Clube 
de Ciências nos países: Costa Rica, Cuba, Equador, El Salvador, Guatemala, Haiti, Honduras, Nicarágua, Panamá e República Dominicana.

Com os Clubes de Ciências identificados, os próximos objetivos consistiram em elaborar um inventário das compreensões e práticas que têm sido mediadoras de suas organizações. Para isso, enviamos um convite por e-mail para cada Clube e, também, buscou-se comunicação por contato via Facebook ou no espaço de comentários dos seus sites.

Apesar dos convites para os cadastros dos Clubes de Ciências na RICC, esse processo ainda é modesto, como se pode observar na tabela 1, quando comparado ao número de Clubes identificados na pesquisa. Desse fato, resultou a divulgação da RICC também em Redes Sociais, como no Pinterest e Facebook, o que já evidenciaram resultados positivos, principalmente para socialização das informações entre os Clubes

Tabela 1. Inventário de Clubes de Ciências e Inscritos na RICC

\begin{tabular}{l|c|c}
\hline \multicolumn{1}{c|}{ PAÍS } & $\begin{array}{c}\text { QUANTIDADE } \\
\text { DE CLUBES } \\
\text { INVENTARIADOS }\end{array}$ & $\begin{array}{c}\text { QUANTIDADE DE } \\
\text { CLUBES INSCRITOS } \\
\text { RICC }\end{array}$ \\
\hline ARGENTINA & 119 & 21 \\
\hline BOLIVIA & 4 & 31 \\
\hline BRASIL & 77 & 1 \\
\hline CHILE & 9 & 3 \\
\hline COLOMBIA & 8 & 1 \\
\hline EQUADOR & 2 & \\
\hline PARAGUAI & 1 & 1 \\
\hline PANAMÁ & $5(143)^{2}$ & \\
\hline PERU & 30 & $\mathbf{5 8}$ \\
\hline URUGUAI & 6 & \\
\hline VENEZUELA & 16 & \\
\hline MEXICO & $\mathbf{2 7 8}(\mathbf{4 2 1 )}$ & \\
\hline TOTAL & & \\
\hline
\end{tabular}

Fonte: Dados da pesquisa (até jul.|2017)

Os 58 Clubes de Ciências já cadastrados na RICC $^{3}$ são representantes da Argentina, Brasil, Colômbia, Chile, Paraguai e Uruguai. Ainda, não cadastrados, a RICC já conta com a parceria da Red Peruana de Divulgadores Científicos que fará a inscrição de seus 143 "Clubs".

Elaboramos uma análise do funcionamento dos Clubes de Ciências a partir da reunião de um conjunto de informações do ponto de vista de seus protagonistas (responsáveis pelos Clubes), coletadas a partir das suas inscrições com o preenchimento do formulário que consta no site e que foi planejado como instrumento de coleta de dados. Além disso, ampliou-se este exame, considerando outros dados disponíveis online, selecionados por meio de observação em sites 
oficiais dos países (Ministérios e Secretarias) ligados à Ciência e Educação, como materiais de divulgação, materiais didáticos, apostilas e outros textos informativos sobre os Clubes de Ciências.

Para caracterizar o funcionamento dos Clubes de Ciências identificamos os requisitos formais/legais (leis, políticas públicas...) que permitem e incentivam a realização do clube no país; seus locais de funcionamento (escola - pública, privada ou outro), iniciativa para implantação do Clube de Ciências, apoio financeiro e parcerias com outras instituições e atividades desenvolvidas. Para tal, sistematizamos as informações investigadas de acordo com o país.

Importante destacar que para este artigo optamos constar informações apenas dos países que já tem representantes inscritos na RICC e que pudemos contar com dados gerados com o formulário:

\section{ARGENTINA}

Os Clubes de Ciências são grupos de crianças, jovens ou adultos guiados por, no mínimo, um assessor maior de idade, que realizam atividades durante todo o ano em torno de temas da ciência, além da dinâmica escolar. Estes grupos realizam projetos científicos, tecnológicos ou sociais. Eles podem ser de investigação ou experimentação, mas não estão limitados a eles. Eles se encontram nas escolas no contraturno, casas particulares e até mesmo em lugares públicos. Não há limite para o número de membros de um clube, não há restrições de idade, classe social ou de nenhuma outra natureza. (ARGENTINA - RdeCC, 2017, tradução nossa).

A Argentina conta com aproximadamente 120 Clubes de Ciências em atividade, conforme identificados na pesquisa online. Inscreveram-se já na RICC 21 Clubes de Ciências de sete províncias (Buenos Aires, Catamarca, Córdoba, Del Chaco, Entre Ríos, Misiones e San Juan). Destes, dois acontecem em espaços educativos de universidades (Universidad Nacional de Lanús, Buenos Aires e Instituto Preuniversitario Escuela Industrial "Domingo F. Sarmiento", Cidad San Juan) e os demais em escolas, com público de nível secundário.

O Clube de Ciências cadastrado na RICC com ano de início de funcionamento mais antigo é de 1985 e os outros variam entre 1998 a 2015, o que sugere a existência destes espaços nas escolas Argentinas há mais de 30 anos.

Os encontros dos clubes acontecem no contraturno escolar ou em sábados, como pode-se notar na resposta de um de seus responsáveis: "El club se reúne, para sus actividades, los sábados por la tarde en un predio de la Universidad Nacional de Lanús”. E uma característica que diferencia o funcionamento deles em relação aos outros países, é que podem ser desenvolvidos além da escola ou universidade, em outros contextos comunitários sob assessoria de um pesquisador, por exemplo.

Durante a pesquisa podemos observar que neste país o funcionamento dos Clubes de Ciências faz parte de uma política e de seu conjunto de ações desenvolvidas pelo Estado, articuladas ao Ministerio de Ciencia, Tecnología e Innovación Productiva:

Os Clubes de ciência possuem um enorme potencial cultural: investigam uma problemática da realidade, se esforçam para compreendê-la e até mesmo avançar em sua solução, 
constituindo-se em espaços importantes para a construção da cidadania e empoderamento. A política ministerial tem por objetivo consolidar e ampliar as ações desses espaços, promovendo ao mesmo tempo a sua multiplicação. (ARGENTINA - MINCYT, 2017, grifo nosso e tradução nossa)

Para isso, o Ministério é responsável pela organização de uma "Red de Clubes de Ciencia", um projeto que faz parte do "Programa Nacional de Popularización de la Ciencia y la Innovación".

\section{A Red de Clubes de Ciencia:}

É uma maneira de conectar clubes de ciência entre si e com os cientistas e tecnólogos, para apoiá-los, para trabalhar e crescer juntos. A Rede se manifesta em diversas formas de intercâmbio de experiências entre os clubes, tais como interações diretas em reuniões presenciais e redes sociais, e espaços de trabalho conjuntos, tais como seminários, capacitações e projetos de ciência cidadã. (ARGENTINA - RdeCC, 2017, tradução nossa)

A Rede conta com um site oficial, com um mapa interativo que permite visualizar informações sobre todos os clubes distribuídos pelo país, bem como a ficha de inscrição para os novos. Além disso, há links com outras explicações sobre os Clubes de Ciências e vídeos informativos do projeto; materiais científicos que consistem em textos para estudantes/clubistas e, também, para formação de professores, chamados de "docentes assessores". Há, também, a divulgação dos "Encontros Nacionais e Regionais dos Clubes de Ciências" e as "Feiras de Ciências", com programações de atividades para os coletivos dos Clubes em funcionamento nas diferentes províncias do país.

Segundo informações coletadas com os responsáveis que se inscreveram na RICC, para o funcionamento de um Clube de Ciências na Argentina é preciso inicialmente registrar-se em um "Programa Provincial de Atividades Científica e Tecnológicas", que regulamenta as ações em nível local, de Província, ${ }^{4}$ e na Red Argentina de Clubes de Ciencia, em um nível de federação. Exemplos disso podem ser observados em excertos de documentos divulgados pelas Províncias, identificados na pesquisa, como em uma convocação para desenvolvimento de projetos da Província de Santa Cruz: "O [projeto] "Clube de Ciências" consiste em convocar os docentes e estudantes das distintas jurisdições da Província que tenham interesse [...] para formar um agrupamento permanente de crianças e jovens orientados por assessores e regidos por um estatuto".(SANTA CRUZ, s.d., p.1, grifo nosso, tradução nossa)

Também, na Lei n. 773, da Província da Terra do Fogo, Antártida e Ilhas do Atlântico Sul (2008) que regulamenta a criação de: Clubes de Ciencias y Tecnología en establecimientos educativos públicos de gestión estatal y privada: creación.

Ainda, no material instrucional da Província de Córdoba:

Um marco das diversas ações que o Governo de Córdoba vem desenvolvendo nos últimos anos com vistas ao fortalecimento e difusão das ciências e tecnologias, convencido de sua importância para formação cultural cidadã [...]Este é o objetivo deste material elaborado para enfatizar a importância da formação do Clube escolar de Ciência e Tecnologia 
como dispositivo sociopedagógico que encontra seus fundamentos na participação de estudantes e professores entorno da ciência e tecnologia. (CÓRDOBA, 202, p. 2, grifo nosso, tradução nossa)

Estes, dentre outros tantos documentos inventariados, permitem interpretar que no país Argentina, os Clubes de Ciências têm seu funcionamento legitimado por políticas públicas que têm como foco "fomentar e estimular a todos estes espaços de educação não formal a geração de uma identidade baseada na autogestão, na exploração e socialização de ideias". (ARGENTINA - RdeCC, 2017, grifo nosso, tradução nossa)

$\mathrm{Na}$ Argentina, os Clubes de Ciências [e de Tecnologia] são organizados no contraturno escolar e os estudantes são agrupados por níveis de escolaridade (inicial, primário, secundário, terciário e universitário) que podem, também, contemplar agrupamentos da modalidade Educação de Jovens e Adultos. Os Clubes de Ciências contam com estatutos próprios, uma equipe de diretoria, livros-ata e precisam divulgar suas atividades (Feiras Científicas e Encontros de Clubes de Ciências). Existe uma programação anual, por regiões, para o Encontro Nacional dos Clubes de Ciências, que são amplamente divulgados no site:

São instâncias privilegiadas de intercâmbio entre os diversos clubes, seus integrantes e o MINCYT. Seu propósito é estabelecer e fortalecer vínculos entre os Clubes, proporcionarlhes capacitações e ferramentas que potencializem a qualidade científica dos projetos e ajude a sustentar seu trabalho ao longo do tempo. Não há instâncias competitivas. Se trabalha em um clima amigável e alegre, com base em colaboração mútua. (ARGENTINA - RdeCC, 2017, tradução nossa)

Com os dados coletados no formulário, por meio de seus protagonistas, podemos descobrir que para o funcionamento dos clubes, há subsídios do Governo em: "As remunerações dos docentes se canalizam por meio de um programa de subsidios para escolas estatais destinado ao fortalecimento educativo, por sua vez a cooperadora do estabelecimento apoia com a compra de materiais e insumos necessários para o funcionamento (responsável por um Clube de Ciências - Argentina)

No inventário observamos, em outros sites a divulgação de materiais para formação dos professores atuantes em Clubes de Ciências (capacitación para asesores de clubes de ciência), em encontros presenciais e também virtuais, à distância. Ainda, observaram-se pesquisas acadêmicas sobre Clubes de Ciências, em trabalhos de conclusão de curso em nível de mestrado, doutorado e divulgadas em anais e eventos e periódicos científicos do país. Também, em sites de compartilhamento público de materiais (como o SlideShare) é possível acessar apresentações e outros textos de professores e pesquisadores argentinos sobre Clube de Ciências, evidenciando a relevância que eles ocupam na Educação Científica do país.

No site da Rede http:// clubes.mincyt.gob.ar/ é possível observar, com mais detalhes, informações e acessar materiais oficiais do governo federal sobre o funcionamento dos Clubes de Ciências na Argentina. 


\section{BRASIL}

$\mathrm{Na}$ pesquisa foram identificados 77 Clubes de Ciências distribuídos pelos estados brasileiros. Destes 31 já se inscreveram na RICC, compreendendo 21 clubes em funcionamento em escolas públicas, $4 \mathrm{em}$ escolas particulares e $6 \mathrm{em}$ universidades. Os Clubes inscritos estão distribuídos nos estados: Bahia, Espírito Santo, Minas Gerais, Pará, Paraná, São Paulo, Santa Catarina, Rio de Janeiro, Rio Grande do Sul e Rondônia.

Existem referências do funcionamento de Clube de Ciências no Brasil desde a década de 1950, como se pode notar em um registro de implantação no "Colégio de Aplicação da Faculdade Nacional de Filosofia" do Rio de Janeiro, no ano de 1959, em que o autor/professor menciona: "Inicialmente procuramos esclarecer aos alunos sobre as iniciativas que poderiam ser patrocinadas por um clube de ciências, mencionando a experiência, nesse terreno, de outros países" (BASTOS, 1959, p. 42, grifo nosso). Outro exemplo da história, Mancuso, Lima e Bandeira (1996, p. 27) destacam em seu livro, ${ }^{5}$ especificamente, no estado do Rio Grande do Sul, na década de 1970, que "explodiram feito pipoca por todo Estado e em muitos Estados do país." Resistiram até a década de noventa... "E a moda dos Clubes deixou de ser moda no momento em que começara a faltar professores nas salas de aula".

O Brasil não tem nenhuma política pública, em nível federal, para o funcionamento dos Clubes de Ciências no país. Também, não foram encontrados materiais de divulgação ou documentos do governo federal (Ministério da Educação ou da Ciência, Tecnologia, Inovações e Comunicações) sobre estes espaços de educação científica.

Em outros contextos de cidades e estados brasileiros em que existem Clubes de Ciências nas escolas ou em funcionamento com a parceria de Universidades, não constam como projetos em sites de Secretarias de Educação. Em nível estadual, constatamos referências às iniciativas particulares de escolas, mas não de redes de ensino ou de secretarias de Educação/Ciência. Disponível online, no inventário encontrou-se apenas um material informativo, da Secretaria Estadual de Educação do Paraná/BR (GUARAPUAVA, 2008) escrito em parceria com a Universidade Estadual Centro-Oeste, sobre Clubes de Ciências, com indicações para sua implementação nas escolas públicas. Observamos neste período, também, um número expressivo de artigos científicos publicados com pesquisas sobre a implementação e funcionamento desses contextos em escolas do Paraná. No entanto, pressupomos que o projeto Clubes de Ciências não teve continuidade na Rede de Ensino, com a mudança de governo no Estado, pois em seu site oficial não consta entre os outros projetos atuais elencados e em atividade.

Os dados produzidos na pesquisa sobre os Clubes de Ciências no Brasil, a partir dos inscritos da RICC, permitem interpretar que o funcionamento ocorre no contraturno escolar, nas dependências da escola, com um professor de Ciências coordenador. Há também, Clubes de Ciências que funcionam nas Universidades e os estudantes que se deslocam para os encontros.

Em sua grande maioria, diferente de outros países, os Clubes têm acompanhamento de estudantes de licenciaturas que desenvolvem atividades de 
docência, como o estágio curricular, atividades de extensão ou do Programa Institucional de Bolsas de Iniciação à Docência (PIBID/CAPES). Importante destacar que esta interface no Brasil dos Clubes de Ciências com as universidades permite a inserção das crianças e adolescentes em um meio acadêmico e ao acesso a bens culturais que ampliam suas escolhas profissionais e o universo de suas comunidades, onde muitos pais têm ainda baixa escolaridade e nunca entraram em uma universidade.

Além disso, constatamos que os Clubes de Ciências, em sua maioria, têm seu funcionamento atrelado a fomento externo, como se pode notar nos excertos em relação à pergunta: "O Clube de Ciências recebe apoio financeiro para o funcionamento? Se sim, de quem?":

- da CAPES, Bolsas de PIBID para que acadêmicos da [licenciatura] FURB atuem na escola e auxilio com material de consumo;

- da Fundação para o Incremento da Pesquisa e do Aperfeiçoamento Industrial (FIPAI) e da Fundação de Amparo à Pesquisa do Estado de São Paulo (Fapesp), por meio de bolsas de iniciação científica para alunos de Licenciatura em Ciências Exatas, que desenvolvem as atividades com os alunos de ensino médio e, no caso da Fapesp, para alguns materiais de consumo previstos em projeto enviado em 2012. Também recebemos apoio financeiro do IEA

Polo São Carlos e do NAPSoL para adquirir demais materiais de consumo.

- conseguimos apoio por meio de editais de fomento do CNPq, CAPES $e$ da própria UFPA, além de manter um convênio com a Secretaria de Estado de Educação do Pará, que cede alguns professores para trabalhar no projeto CCIUFPA e Projeto de pesquisa e extensão aprovados pelos professores do Instituto de Educação Matemática e Científica da Universidade Federal do Pará.

-Apoio financeiro da FAPESP e da Pró-Reitoria de Graduação da USP com a disponibilização de bolsistas, que são os tutores do Clube.

- Prefeitura Municipal de Abaetetuba - cedência de funcionários e pagamento da conta de lu₹; SEDUC/PA - cedência de funcionários; IFPA Campus Abaetetuba e UFPA Campus Abaetetuba - apoio.

- Recebe apoio da própria universidade e, neste ano, do CNPq, tanto com materiais de consumo e serviços quanto com bolsas de iniciação científica júnior para alguns participantes.

Nesta direção, alguns Clubes de Ciências são desenvolvidos nos próprios espaços físicos das Universidades (campus da USP São Carlos, USP São Paulo, Universidade Federal do Paraná, Instituto Federal Pará, Centro de Pesquisa e Inovação em Biodiversidade e Fármacos (CIBFar/CEPID/FAPESP). E a maioria desses projetos tem como ênfase a formação inicial de professores (Ciências, Física, Química e Biologia), envolvendo as licenciaturas. Mesmo quando acontecem em escolas públicas, como no caso de cinco Clubes de Ciências da cidade de Blumenau/ SC, têm interfaces com a Universidade com apoio de projetos de extensão e CAPES/PIBID (Programa Institucional de Bolsa de Iniciação à Docência). 
Se por um lado, este panorama revela uma importante relação da Universidade brasileira com a escola de Educação Básica, no desenvolvimento da educação científica e de uma formação de professores (inicial e continuada) para atuação nesse contexto, por outro lado aponta a fragilidade das condições materiais para o funcionamento dos Clubes de Ciências no país, dependentes de recursos sempre atrelados a determinadas gestões públicas ou aos órgãos de fomento à pesquisa e extensão. Quando se trata de recursos públicos de Secretarias de Educação, municipais e estaduais, geralmente quando há redução de custos, acontece o corte das horas-aulas dos professores de Ciências que desenvolvem atividades com Clubes de Ciências, desfavorecendo a sua continuidade nas escolas.

Os Clubes de Ciências brasileiros não possuem uma dinâmica, como em outros países, de Encontros ou Feiras Científicas que legitimam a sua identidade no país. Existem iniciativas locais, como na cidade de Blumenau/Santa Catarina em que os Clubes de Ciências têm um encontro anual, em uma das escolas polo de Clubes de Ciências, e participam da Feira Científica em conjunto com a Mostra Interna de Pesquisa, Ensino e Extensão da FURB.

Com a pesquisa foi possível evidenciar da importância que a RICC terá para reunir os Clubes de Ciências brasileiros e, quem sabe, possibilitar uma maior expressão e legitimidade para o fomento de programas públicos de incentivo para o seu funcionamento no Brasil.

\section{COLÔMBIA, BOLÍVIA E MÉXICO}

Embora somente Clubes de Ciências da Colômbia já tenham se cadastrado na RICC, outros dois países, a Bolívia e o México, possuem similaridades nas organizações para os funcionamentos de Clubes de Ciências. Em comum, os três países fazem parte de uma Rede constituída pela iniciativa de jovens cientistas e investigadores hispano-americanos que estudam em universidades, como Harvard, MIT, Stanford, Princeton, Babson College que promovem os Clubes de Ciências, estabelecendo colaborações com investigadores/as e instituições nos países. Para isso, buscam recursos financeiros, planejam os programas e recrutam instrutores/as e estudantes para participarem. Em cada país há um grupo de voluntários responsável pela organização dos Clubes de Ciências, a manutenção do site, a organização das convocatórias para participação e toda logística para os encontros acontecerem.

Os Clubes de Ciências nestes países funcionam como cursos intensivos gratuitos, geralmente em uma semana de duração em diversos temas das áreas STEM (Science, Technology, Engineering, Math), para jovens que estão cursando últimos anos da escola secundária em instituições públicas e primeiros anos da universidades.

Em programações de datas e locais divulgadas nos sites, convocamse os instrutores/as e estudantes para o acontecimento dos Clubes de Ciências em cidades dos países, geralmente em convênio com outras universidades do país. "Cada clube da ciência é liderado por um pesquisador (tipicamente estudante de doutorado ou pós-doutorado) de uma instituição no exterior, trabalhando em conjunto com um co-instrutor de uma instituição colombiana [ou mexicana, boliviana] e destina-se a um grupo de 15 a 20 alunos". Esta dupla de instrutores planeja um Clube de Ciências e divulga a ideia. (CDEC - Col, 2017) 
Durante a semana do Clube de Ciências, os estudantes participam de atividades e simpósios em que os instrutores explicam o tema de investigação. A partir disso, promovem-se a criação de redes de colaboração entre os participantes e a comunidade científica para investigação e/ou experimentação de temas, que podem durar até seis meses.

Os países contam com sites e redes sociais atualizadas, com vídeos explicativos, fotos e textos de relatos de experiências, bem como os números de participantes (estudantes e instrutores) envolvidos. Estes podem ser acessados: México: http://www.clubesdeciencia.mx/; Bolívia: http://www. clubesdecienciabolivia.com/ e Colômbia:http:/ /www.clubesdeciencia.co/

Importante destacar que cada país tem um texto explicativo em comum da proposta na página de abertura do site, no entanto apresentam especificidades para o funcionamento dos Clubes de Ciências em seu país. Tal fato assevera a importância desse projeto (voluntário) de Clubes de Ciências para estes países latino-americanos. Destaca-se que os Clubes de Ciências, com exceção da Bolívia, constam em suas páginas com o logotipo e apoio de Ministérios dos seus países e de outros patrocinadores de instituições públicas e privadas.

Além desse projeto, foi possível constatar na pesquisa, que existem também iniciativas de escolas que promovem o funcionamento de Clubes de Ciências para escolares da Educação Básica nestes países. Destas, já dois Clubes colombianos e o Club Científico do Zoológico de Santa Fé se cadastraram na RICC no período de coleta de dados.

\section{PERU}

No Peru também existe uma ação do governo federal para o funcionamento dos Clubes de Ciências. Na pesquisa, constatou-se um link no site do Consejo Nacional de Ciencia, Tecnología e Innovación Tecnológica do país específico para os Clubes de Ciências: http://www.concytec.gob.pe/eureka/index.php/clubes-de-ciencia-y-tecnologia.

Os clubes surgiram a partir das Feiras de Ciências, que foram apontando exigências para uma organização nas escolas para educação científica.

Segundo os dados coletados, no ano de 2015 a Dirección Nacional de la Red Peruana de Divulgadores Científicos convoca a organização de uma Red Nacional de Clubes de CyT no país e estabelece um documento norteador para o funcionamento dos Clubes de Ciências. Estes precisam solicitar um registro oficial do Consejo Nacional de Ciencia, Tecnología e Innovación Tecnológica (CONCYTEC), acompanhando um plano de atividades semestral ou anual.

O Manual de Clubes de Ciencia y Tecnología apresenta definições, objetivos, diretrizes para implantação e desenvolvimento do Clube, bem como o regulamento e atividades que podem ser desenvolvidas.

Um aspecto diferente, dos outros países, é que o funcionamentos dos Clubes de Ciências conta, também, com um Conselho Consultivo, integrado por três professores (de preferência de Ciências e Tecnologia), três pais de família e três cientistas. A participação desses membros garante que recebam ao finalizar o ano letivo uma declaração de participação emitida pelo CONCYTEC, válida para postular bolsas de estudo do Programa Nacional (PRONABEC), incentivando esta relação entre escola-família-universidade. 
$\mathrm{Na}$ pesquisa não foi possível observar sites dos Clubes de Ciências específicos das escolas, mas sabe-se da existência deles pelos registros de informações e imagens no site oficial do governo, bem como em listas de clubes participantes nas Feiras científicas.

\section{CHILE}

Durante a realização da pesquisa foram encontrados, na busca online, nove Clubes de Ciências no Chile, que ainda não se inscreveram na RICC. Infere-se que existam mais, pois foram observadas informações sobre Feiras de Ciências em que eram noticiados outros clubes de Ciências, porém não foram encontrados na internet, pela busca de seus nomes.

Infere-se que os clubes chilenos tenham seu funcionamento semelhante aos do Brasil, no contraturno escolar, acompanhados pelo professor de Ciências, por iniciativas de escolas. Não foi encontrado nenhum material explicativo, nem informações nos sites dos Ministérios da Educação ou de Ciência do país.

Por outro lado, existe um portal denominado Club de Ciências Chile: http:/ / www.clubcienciaschile.cl/, que reúne informações variadas de atividades científicas desenvolvidas com o público juvenil do país, promovido pelo Centro Cultural Club Ciencias Chile. Este é um representante do "Movimento Internacional para atividades de lazer em Ciência e Tecnologia” (MILSET), ${ }^{6}$ um organização independente que desenvolve e divulga atividades de educação científica em diferentes países.

Dentre os clubes identificados online do Chile, um de destaque é o Club de Ciencias "Abre tu Mundo" da Escuela Viña La Cruz de Coltauco, que tem divulgado suas atividades desde 2006, com expressiva participação de seus estudantes clubistas e professor responsável nos eventos científicos em diferentes países latino-americanos.

\section{URUGUAI}

Um Clube de Ciências do Uruguai já se cadastrou na RICC, no entanto o país tem uma quantidade expressiva destes contextos de Educação Científica distribuídos pelo país. Fato constatado em notícia no site do Ministério de Educación y Cultura sobre a Feira Nacional de Clubes de Ciência:

A Feira é uma instância anual que reúne os Clubes de todo país [...] na qual socializam suas experiências e fazem o intercâmbio com seus pares em ambiente de solidariedade de cooperação. Neste ano, se registraram 808 Clubes de Ciência de 115 localidades que participaram das dezenove Feiras Departamentais. (URUGUAY- MEC, 2017, tradução nossa)

Ainda, consta informação que há mais de 30 anos existem os Clubes de Ciências no país. Suas ações estão vinculadas ao Departamento denominado "Cultura Científica", do Ministério da Educação e Cultura (MEC) que tem um espaço específico em seu site para informações: http:/ / educacion.mec.gub.uy/ innovaportal/ v/85381/5/mecweb/clubes-de-ciencia

Para o funcionamento dos Clubes de Ciências é preciso ter o registro com um formulário que consta no site do MEC ou com o Gestor Departamental 
(designação para a divisão política do país, semelhante no Brasil aos estados). O orientador do Clube pode ser um professor, um membro da comunidade ou outra pessoa com qualidades para acompanhar as investigações e atividades do coletivo. Os Clubes precisam participar de Congressos e Feiras em seus Departamentos e na Feira Nacional.

Existem no país sete categorias para o funcionamento dos Clubes de Ciências, que incluem grupos da Educação Infantil até maiores de 29 anos. Podem estar localizados em contextos formais (escolas e universidades), como, também, em outros cenários que possa permitir o desenvolvimento de investigações científicas (Casa da Cultura, Museus, MEC...)

Em leitura de materiais disponibilizados pelo MEC podemos observar que o regulamento para o funcionamento dos clubes está diretamente relacionado à Feira Nacional de Clubes de Ciências, que tem muito destaque de suas edições, em diferentes informativos em sites de divulgação científica e jornais do país. Constatamos, também, cursos oferecidos a distância para aprofundamento sobre Clubes de Ciências para professores ou participantes. Além disso, observou-se que o Clube de Ciências é objeto de estudo de pesquisas divulgadas em eventos e periódicos científicos do país, evidenciando sua importância também para a comunidade acadêmica do Uruguai.

\section{PARAGUAI}

Na RICC houve a inscrição de um Clube de Ciências do Paraguai, o Club de Ciencias CEC (http://clubcecscience.blogspot.com.br/)Em seu site foi possível observar uma postagem com a informação de que "A primeira atividade a ser realizada pelo Clube será a organização de um encontro científico entre estudantes interessados em viver experiências que incentivem a formação de Red de Clubes de Ciencias en el Paraguay". (CEC, 2017, tradução nossa). No entanto, não se identificou nenhuma efetivação deste projeto ou outro Clube de Ciências, bem como, informações em outros sites oficiais que permitem identificar os clubes e seu funcionamento no país.

Em síntese, reunimos no quadro 1 um panorama de informações que permitem diferenciar o apoio, os modos de funcionamento e os participantes dos Clubes de Ciências nos países em que inventariamos: 
Mapeamento dos clubes de ciências da América Latina e construção do site da Rede Internacional de Clubes de Ciências

Quadro 1. Panorama do funcionamento dos Clubes de Ciências em países da América Latina

\begin{tabular}{|c|c|c|c|}
\hline$\frac{n}{\pi}$ & Apoio ao funcionamento & Modo de funcionamento & Participantes \\
\hline 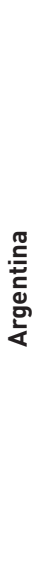 & $\begin{array}{l}\text { Política Pública, Vinculado } \\
\text { ao do Ministério de Ciência, } \\
\text { Tecnologia e Inovação. }\end{array}$ & $\begin{array}{l}\text { Encontros semanais na } \\
\text { escola no contra turno; ou } \\
\text { sábados nas universidades; } \\
\text { ou em datas combinadas } \\
\text { em outras instituições para } \\
\text { desenvolvimento de projetos } \\
\text { investigativos. } \\
\text { Participam de Encontros } \\
\text { Nacionais e Regionais dos } \\
\text { Clubes de Ciências } \\
\text { Participam de Feiras de } \\
\text { Ciências, com programações } \\
\text { de atividades para os } \\
\text { coletivos dos Clubes } \\
\text { em funcionamento nas } \\
\text { diferentes províncias do país }\end{array}$ & $\begin{array}{l}\text { Estudantes são agrupados } \\
\text { por níveis de escolaridade } \\
\text { (inicial, primário, } \\
\text { secundário, terciário e } \\
\text { universitário), também há } \\
\text { a modalidade Educação de } \\
\text { Jovens e Adultos. } \\
\text { Coordenado por Professor } \\
\text { de Ciências ou um } \\
\text { Pesquisador. }\end{array}$ \\
\hline 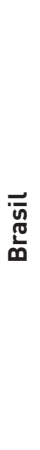 & $\begin{array}{l}\text { Iniciativas isoladas de } \\
\text { escolas, redes de ensino } \\
\text { e de Universidades com } \\
\text { projetos em Programas } \\
\text { de extensão) ou Agências } \\
\text { (CAPES, FAPEs, CNPq ...) }\end{array}$ & $\begin{array}{l}\text { Encontros semanais na } \\
\text { escola ou nas universidades } \\
\text { para desenvolvimento de } \\
\text { projetos investigativos ou } \\
\text { experimentações. }\end{array}$ & $\begin{array}{l}\text { Geralmente formado por } \\
\text { estudantes de anos finais. } \\
\text { Não foi identificado nenhum } \\
\text { Clube com crianças de anos } \\
\text { iniciais. } \\
\text { Coordenado por } \\
\text { professores de Ciências } \\
\text { nas escolas ou nas } \\
\text { Universidades por } \\
\text { docentes das Ciências da } \\
\text { Natureza, geralmente com } \\
\text { licenciandos. }\end{array}$ \\
\hline 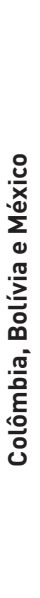 & $\begin{array}{l}\text { Iniciativa de uma } \\
\text { Organização sem fins } \\
\text { lucrativos de jovens } \\
\text { cientistas e investigadores } \\
\text { hispano-americanos. }\end{array}$ & $\begin{array}{l}\text { Programação anual, } \\
\text { envolvendo a criação de } \\
\text { Clubes por temáticas de } \\
\text { investigação. } \\
\text { Durante uma semana os } \\
\text { estudantes participam de } \\
\text { atividades e simpósios em } \\
\text { que os instrutores explicam } \\
\text { o tema de investigação. A } \\
\text { partir disso, promovem- } \\
\text { se a criação de redes } \\
\text { de colaboração entre os } \\
\text { participantes e a comunidade } \\
\text { científica para investigação } \\
\text { e/ou experimentação de } \\
\text { temas, que podem durar até } \\
\text { seis meses. }\end{array}$ & $\begin{array}{l}\text { Jovens que estão cursando } \\
\text { últimos anos da escola } \\
\text { secundária em instituições } \\
\text { públicas e primeiros anos } \\
\text { da universidade. } \\
\text { Cada clube é liderado } \\
\text { por um pesquisador } \\
\text { (estudante de doutorado } \\
\text { ou pós-doutorado) de uma } \\
\text { instituição no exterior, } \\
\text { trabalhando em conjunto } \\
\text { com um co-instrutor de } \\
\text { uma instituição do país } \\
\text { sede e reúne um grupo de } \\
15 \text { a } 20 \text { alunos. }\end{array}$ \\
\hline
\end{tabular}




\begin{tabular}{|c|c|c|c|}
\hline & $\begin{array}{l}\text { Iniciativa do Centro Cultural } \\
\text { Club Ciencias Chile. Este } \\
\text { é um representante do } \\
\text { "Movimento Internacional } \\
\text { para atividades de lazer } \\
\text { em Ciência e Tecnologia" } \\
\text { (MILSET), uma organização } \\
\text { independente que } \\
\text { desenvolve e divulga } \\
\text { atividades de educação } \\
\text { científica em diferentes } \\
\text { países. }\end{array}$ & $\begin{array}{l}\text { Encontros semanais na } \\
\text { escola no contra turno para } \\
\text { desenvolvimento de projetos } \\
\text { investigativos. }\end{array}$ & $\begin{array}{l}\text { Estudantes organizados } \\
\text { em categorias de nível } \\
\text { inicial (educação infantill), } \\
\text { primário e secundário. } \\
\text { O coordenador do Clube é } \\
\text { um professor da escola. }\end{array}$ \\
\hline$\frac{\vec{J}}{0}$ & $\begin{array}{l}\text { Política Pública, Vinculado } \\
\text { ao Consejo Nacional de } \\
\text { Ciencia, Tecnología e } \\
\text { Innovación Tecnologica } \\
\text { (CONCYTEC) }\end{array}$ & $\begin{array}{l}\text { Encontros semanais na } \\
\text { escola no contra turno. } \\
\text { Participam da Feira Escolar } \\
\text { Nacional de Ciência e } \\
\text { Tecnologia, Olimpíadas } \\
\text { científicas e Encontros } \\
\text { anuais dos Clubes, } \\
\text { organizados pelo Ministério } \\
\text { de Educação e CONCYTEC }\end{array}$ & $\begin{array}{l}0 \text { coordenador do Clube é } \\
\text { um professor da escola. } \\
\text { Conta, também, com um } \\
\text { Conselho Consultivo, } \\
\text { integrado por três } \\
\text { professores, três pais de } \\
\text { família e três cientistas. }\end{array}$ \\
\hline 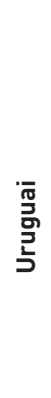 & $\begin{array}{l}\text { Política Pública, Vinculado } \\
\text { ao Departamento "Cultura } \\
\text { Científica", do Ministerio de } \\
\text { Educación y Cultura }\end{array}$ & $\begin{array}{l}\text { Encontros semanais na } \\
\text { escola no contra turno ou } \\
\text { outras instituições sociais } \\
\text { (casa da cultura, museus...). } \\
\text { Participam de Congressos } \\
\text { e Feiras em seus } \\
\text { Departamentos e na Feira } \\
\text { Nacional. }\end{array}$ & $\begin{array}{l}\text { Diferentes agrupamentos } \\
\text { da Educação Infantil até } \\
\text { maiores de } 29 \text { anos. } \\
0 \text { coordenador do } \\
\text { Clube pode ser um } \\
\text { professor, um membro } \\
\text { da comunidade ou outra } \\
\text { pessoa com qualidades } \\
\text { para acompanhar as } \\
\text { investigações e atividades } \\
\text { do coletivo. }\end{array}$ \\
\hline
\end{tabular}

Fonte: Dados da pesquisa (até jul./2017)

Para além dessas informações, constatamos que, em comum, os Clubes de Ciências dos diferentes países pesquisados desenvolvem atividades com estudantes clubistas, com espírito de cooperação, relacionadas ao desenvolvimento de conhecimentos e o gosto pela ciência e tecnologia, com investigações, experimentos, saídas a campo, interlocuções com cientistas, dentre outras.

Os temas de investigação são escolhidos de forma democrática entre clubistas e professor e geralmente são em relação às problemáticas observadas na comunidade ou país, interesses dos estudantes e, também, podem estar veiculadas aos temas curriculares. Para isso, estabelecem parcerias com outras instituições citadas: Escolas, Museus, Universidades, ONGs, Prefeituras e Secretarias Municipais. Os 
Clubes de Ciências têm atividades com interfaces com espaços de universidades e relações com cientistas/pesquisadores, fazendo entrevistas, correspondência, videoconferências, visitas aos laboratórios e outros espaços das universidades.

Ainda, observamos o desenvolvimento de atividades culturais com cineciências, teatros, jogos e dinâmicas de grupos. E atividades de recreação, lanches coletivos, evidenciando um clima de amizade e de constituição de boas relações sociais. Há, também, um enfoque na divulgação das atividades desenvolvidas com: informativos, em sites, blogs, redes sociais (especialmente no Brasil) e nas atividades desenvolvidas pelos países com os Encontros dos Clubes de Ciências e as Feiras de Ciências regionais e nacionais (com destaque para Uruguai, Argentina e Peru).

\section{CONSTRUC̣ÃO DO SITE DA REDE INTERNACIONAL DE CLUBES DE CIÊNCIAS}

Como descrito no percurso investigativo, elaboramos o site da Rede Internacional de Clubes de Ciências (RICC): http://www.clubesdeciencias. $\mathrm{com} /$. Esse, em um primeiro momento, serviu para alocar o formulário que empregamos para coletar dados, a partir das respostas dos professores/ coordenadores dos Clubes de Ciências. Por conseguinte, o site tornou-se um produto da pesquisa, pois permitiu a inscrição dos Clubes e a sua reunião em um espaço virtual comum, favorecendo o desenvolvimento de uma "rede" de interlocução entre eles, bem como de visibilidade para esse contexto de educação científica.

Para sua construção, adquirimos o domínio do site e elaboramos o logotipo, com a ideia de uma rede que interliga os mapas dos diferentes países da América Latina. Na figura 1 observa-se o template do site, onde é possível identificar o mapa que contém os Clubes de Ciências que já realizaram a sua inscrição para fazer parte da RICC.

Além do mapa interativo que permite visualizar geograficamente o Clube de Ciências em cada país, e com zoom o seu endereço para contato, o site foi elaborado com links:

- Início: com a apresentação e convite para cadastro do Clube de Ciências. Com o preenchimento do formulário Google. Isto agregou facilidade na constante atualização das informações, pois a ferramenta permite visualizar dados por Clube, e, na síntese, agrupando as informações quantitativas em gráficos e as qualitativas em categorias textuais;

- Quem somos e Apoio: aborda uma apresentação sobre o projeto e seus objetivos, bem como divulga a equipe que coordena e os órgãos fomentadores da pesquisa: CNPq e da nossa Universidade;

- Clubes participantes: traz o inventário dos Clubes com seus links de acesso por países;

- Notícias e Eventos: que será um canal de divulgação de atividades desenvolvidas pela América Latina sobre Clubes de Ciências, atualizado via projeto de extensão da universidade; 
- Contato: com endereço da Universidade Regional de Blumenau e dos contatos de professores e bolsistas (iniciação científica e extensão), para comunicação.

- Biblioteca: reúnem vídeos, artigos científicos, teses, dissertações, documentos e e-books sobre Clubes de Ciências que podem ser acessados por pesquisadores, professores e outros interessados em Clubes de Ciências. Durante a realização da pesquisa foram cadastrados 50 referências de materiais, em português e espanhol, produzidos em diferentes países.

Atualmente, o gerenciamento do site da Rede Internacional de Clubes de Ciências (RICC) é realizado como uma ação extensionista da universidade, permitindo sua continuidade e a possibilidade de desenvolver trabalhos integrados entre pesquisa e extensão, envolvendo especialmente acadêmicos de cursos de licenciatura e da pós-graduação. Do mesmo modo, a biblioteca do site tem recebido várias colaborações de pesquisadores brasileiros que têm o Clube de Ciências como objeto de estudo. Igualmente, outras universidades e professores da Educação básica encontram nesse espaço informações de outros Clubes que podem se inspirar em seus percursos formativos, como evidenciamos em e-mails compartilhados.

Um dos desafios para RICC é ampliar as interlocuções entre os próprios Clubes de Ciências, de modo que os estudantes da Educação Básica e seus professores compartilhem suas experiências nas escolas dos diferentes países.

Figura 1. Template do site RICC

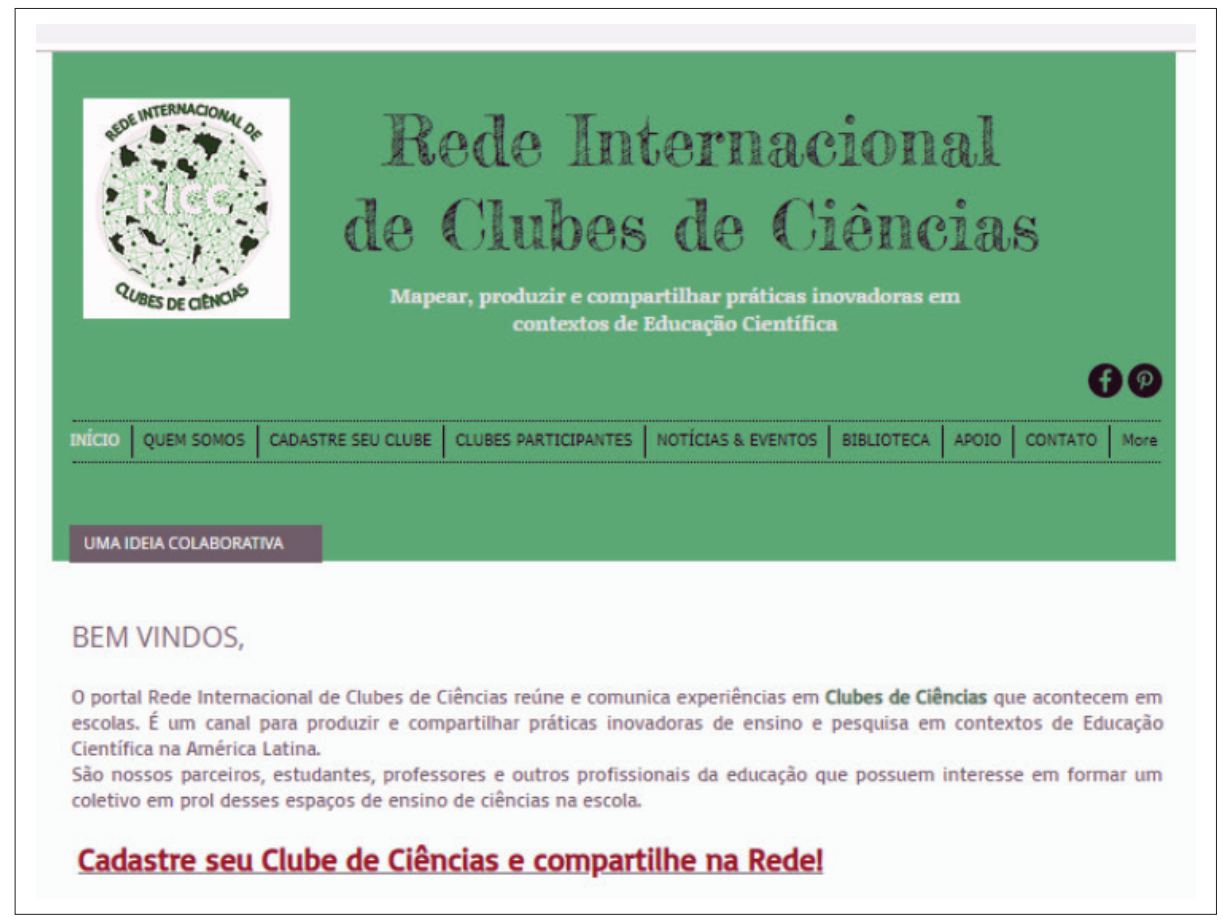

Fonte: Rede Internacional de Clubes de Ciências (2018) 


\section{CONSIDERACְÕES FINAIS}

Com o conhecimento produzido nesta pesquisa concluímos que os Clubes de Ciências são espaços de aprender com relevância para educação científica de um país. Foi possível constatar que na América Latina, países como Argentina, Peru e Uruguai possuem políticas públicas preocupadas com o desenvolvimento da ciência, tecnologia e inovação a partir do ensino de Ciências para suas crianças e jovens. Países como, Colômbia, México, Bolívia, Chile contam com parcerias de organizações não governamentais que buscam aprimorar e incentivar o funcionamento dos Clubes de Ciências. No Brasil existem iniciativas, ainda isoladas, sem respaldos de uma política que legitime estes espaços, muitos deles em funcionamento graças aos projetos de universidades que buscam fomento para desenvolverem parcerias com as escolas públicas.

A pesquisa permitiu aprender sobre estes contextos em sua diversidade de experiências, com a constituição de um banco de informações, favorecendo a produção, difusão e intercâmbio de saberes entre "clubistas", "professores de Ciências", bem como a ampliação de outras pesquisas com objeto de estudo em Clubes de Ciências, com a possibilidade de compartilhar coletivamente experiências que contribuam para a interinstitucionalidade e internacionalização em ações cooperativas de produção e socialização do conhecimento científico sobre e na escola.

\section{AGRADECIMENTOS}

- Ao CNPq pelo apoio à iniciação científica com a concessão de uma bolsa de pesquisa para Bolsista de graduação.

- À Pró-reitoria de Pesquisa e Extensão da Universidade Regional de Blumenau pelo apoio com a concessão de uma bolsa de extensão para Bolsista de graduação.

\section{REFERÊNCIAS}

ARGENTINA. MINISTERIO DE CIENCIA, TECNOLOGÍA E INNOVACIÓN PRODUCTIVA. Red de Clubes de Ciencia. Disponível em: <http://clubes.mincyt.gob.ar> Acesso em: 10 mai. 2017

BERNET, J. T. , La Educación No Formal. In: URUGUAY- Ministerio de Educación y Cultura. Educación No Formal: Lugar de conocimientos: Selección de textos. Montevideo: Dirección de Educación del Mec, 2013. p. 27-51.

BASTOS, C. Clubes de Ciências do Colégio de Aplicação. Revista Escola Secundária, Rio de Janeiro, n. 10, p. 42-4, 1959.

CLUB DE CIENCIA BOLÍVIA. Disponível em: < http://www.clubesdecienciabolivia.com>. Acesso em: 12 ago. 2017. 
CLUB DE CIENCIA COLÔMBIA. Disponível em: < http://www.clubesdeciencia.co> Acesso em: 12 ago. 2017.

CLUB DE CIENCIAS CEC. Disponível em: <http://clubcecscience.blogspot.com.br/> Acesso em: 10 jul. 2017.

CLUB DE CIÊNCIAS CHILE. Disponível em: < http://www.clubcienciaschile.cl/>. Acesso em: 10 jul. 2017.

CLUB DE CIENCIA LATIN AMERICA. Colômbia, México, Bolívia. Disponível em: < http:/ / www.clubesdeciencia.org/> Acesso em: 12 ago. 2017

CLUB DE CIENCIA MÉXICO. Disponível em: http://www.clubesdeciencia.mx/> Acesso em: 12 ago. 2017.

CÓRDOBA. Club Escolar de Ciencias y Tecnologias. Disponível em: < http://www. igualdadycalidadcba.gov.ar/SIPEC-CBA/publicaciones/documentos/ Clubdeciencia2025-7-12. pdf>. Acesso em: 12 abr. 2017.

GUARAPUAVA. SECRETARIA DE ESTADO DA EDUCAÇÃO PARANÁ. UNIVERSIDADE ESTADUAL DO CENTRO - OESTE. Guia de orientações para implementação de um Clube de Ciências. Disponível em: < www.diaadiaeducacao.pr.gov.br/portals/ pde/arquivos/172-2.pdf>. Acesso em: Acesso em: 12 abr. 2017.

MANCUSO, R.; LIMA, V. M. R.; BANDEIRA, V. Clubes de Ciências: criação, funcionamento, dinamização. Porto Alegre: SE/CECIRS, 1996.

MENEZES, C.; SCHROEDER, E.; SILVA, V. L. de S. Clubes de Ciências como espaço de Alfabetização Científica e Ecoformação. Atos de Pesquisa em Educação, Blumenau, v. 7, n. 3, p. 811-833, 2012.

MENEZES, C.; SCHROEDER, E. Clubes de Ciências: contribuições para a educação científica e o desenvolvimento da criatividade nas escolas. IN: SCHROEDER, E.; SILVA, V. L. de S. Novos Talentos: Processos Educativos em Ecoformação. Blumenau: Nova Letra, 2014.

PERU. CONSEJO NACIONAL DE CIENCIA, TECNOLOGIA Y INNOVACION TECNOLÓGICA. Clubes de Ciencia y Tecnologia. Disponível em: < http://www.concytec.gob. pe/eureka/index.php/clubes-de-ciencia-y-tecnologia>. Acesso em: 10 jul. 2017.

PRÁ, G. de; TOMIO, D. . Clube de Ciências: Condições de Produção da Pesquisa em Educação Científica no Brasil. Alexandria, Florianópolis, v. 7, p. 179-207, 2014.

REDE INTERNACIONAL DE CLUBES DE CIÊNCIAS. Site oficial. Disponível em: < http:/ / www.clubesdeciencias.com/ > Acesso em: 12 jul. 2018.

ROCHA, N. M. ; KERN, F.C.; MELO, E. J. ; TOMIO, D. . Como seria se não fosse como é: compartilhando a experiência da inclusão inversa em Clubes de Ciências. In: VII ENCONTRO REGIONAL SUL DO ENSINO DE BIOLOGIA, 2015, Anais..., Criciúma, UNESC, 2015.

SANTA CRUZ. CONSEJO PROVINCIAL DE EDUCACIÓN COORDINACIÓN DE ACTIVIDADES CIENTÍFICAS Y TECNOLÓGICAS JUVENILES. Nombre del proyecto “Club de Ciencias” Disponível em: <https://dpegp.files.wordpress.com/2011/05/ club_de_ ciencias.pdf > Acesso em: 12 jul. 2017. 
SANTOS, L. P. Clube de Ciências: Produção científica no Brasil entre 2013 e 2016. Revista da SBEnBio, Bahia, v. 9, p. 4336-4343, 2016. Disponível em: < http://www.sbenbio.org.br/wordpress/ wp-content/uploads/renbio-9/pdfs/2203.pdf>. Acesso em: 30 jun.2017.

SCHMITZ, V. Um clube... Na escola: identidade e interfaces com a educação (não formal) a partir de uma revisão sistemática. Dissertação de Mestrado - Curso de Pós-graduação em Educação, Universidade Regional de Blumenau, 2017.

TIERRA DEL FUEGO, ANTÁRTIDA E ISLAS DEL ATLÁNTICO SUR. Ley nº 773 Educación: Clubes de ciencias y tecnología en establecimientos educativos públicos de gestión estatal y privada: creación. Sanción: 20 nov. 2008. Disponível em: < www.legistdf.gov.ar/lp/leyes/index.php?dir... LEYP773.pdf>. Acesso em: 10 jul. 2017.

URUGUAY. Ministério de Educación y Cultura. Clubes de Ciência. Disponível em: < http://educacion. mec.gub.uy/innovaportal/ v/85381/5/mecweb/clubes-de-ciencia>. Acesso em: 10 jul. 2017.

\section{NOTAS}

${ }^{1}$ Os dados referentes à organização dos quadros com a identificação dos Clubes de Ciências por país não consta no artigo, pois têm 13 páginas.

${ }^{2}$ Quando o relatório da pesquisa já estava já estava concluído, recebemos a mensagem do Coordenador de Clubes de Ciências do Peru, solicitando a inclusão de seus 143 Clubes. Estes Clubes não puderam ser adicionados, pois ainda não recebemos os endereços de cada um deles para que se possa adicioná-los ao mapa da RICC.

${ }^{3}$ Esses dados da RICC se referem ao período de desenvolvimento da pesquisa.

${ }^{4} \mathrm{Na}$ Argentina, o país é dividido politicamente em regiões geográficas, de acordo com características comuns de clima e relevo, e estas agrupam as províncias.

${ }^{5}$ A obra Clubes de Ciências: criação, funcionamento e dinamização é o único livro no Brasil, do ano de 1996, sobre Clubes e é referência para a maioria das pesquisas sobre esse contexto de educação científica não formal.

6 “O Movimento Internacional para atividades de lazer em Ciência e Tecnologia (MILSET-Mouvement International pour le Loisir Scientifique et Technique) é uma organização de juventude politicamente independente, que visa desenvolver a cultura científica entre os jovens através da organização de programas e ciência-tecnologia, incluindo feiras de ciências, campos de ciência, congressos e outras atividades de alta qualidade". (MILSET BRASIL, 2017) http://www.milsetbrasil.com/

\section{Submetido em 04/03/2018 \\ Aprovado em 31/12/2018}

\section{Contato:}

Daniela Tomio

Rua Max Hering, n. 448, ap. 501 - Bairro Victor Konder

CEP 89.012-510 - Blumenau, Santa Catarina - Brasil 